\title{
Repeatability of sperm size in outbred and inbred Scathophaga stercoraria (Diptera: Scathophagidae)
}

\author{
G. Bernasconi ${ }^{1,2}$ \\ Institute for Environmental Sciences, University of Zurich, Winterthurerstrasse 190, \\ CH-8057 Zurich, Switzerland \\ P.I. Ward \\ Zoological Museum, University of Zurich, Winterthurerstrasse 190, CH-8057 Zurich, \\ Switzerland \\ B. Hellriegel \\ Anthropological Institute and Museum, University of Zurich, Winterthurerstrasse 190, \\ CH-8057 Zurich, Switzerland
}

\begin{abstract}
Variability in male gametic traits can depend on several genetic and environmental factors such as developmental instability as a consequence of inbreeding, developmental noise during spermatogenesis, or age- or condition-dependent changes in allocation to sperm cells. Variation in sperm size is particularly evident in species that produce more than one sperm morph but also occurs among males in sperm-monomorphic species. Both discrete and continuous sperm size variation have been implicated in male fertilization success when the sperm of several males directly compete for fertilization of the same set of ova. In this study, we investigated among-male variation in sperm length in field-collected, outbred male Scathophaga stercoraria (L.) flies, as well as in flies from the same natural population that had been subjected to 15 and 16 generations of inbreeding under laboratory conditions. Among-male variation in sperm length was significant and repeatable over subsequent matings in both inbred and outbred flies. We conclude that sperm length can be used as an individual male marker in sperm competition studies and that significant repeatability of sperm length supports heritability for this trait.
\end{abstract}

Résumé-La variation dans les caractéristiques des gamètes peut dépendre de plusieurs facteurs génétiques et environnementaux, tels que l'instabilité du développement causée par la consanguinité, les perturbations (bruit) dans le développement durant la spermatogenèse et les changements reliés à l'âge ou à la condition dans l'allocation des ressources aux cellules spermatiques. La variation dans la taille des spermatozoïdes est particulièrement évidente chez les espèces qui produisent plus d'un morphe de spermatozoïdes, mais elle est présente aussi chez les mâles à sperme monomorphe. Des variations, tant discrètes que continues, dans la taille des spermatozoïdes ont été invoquées pour expliquer le succès de la fécondation lorsque plusieurs mâles sont en compétition pour féconder la même masse d'oeufs. Dans notre étude, nous avons déterminé la variation d'un mâle à l'autre de la longueur des spermatozoïdes chez des mouches mâles Scathophaga stercoraria (L.) non consanguines et récoltées en nature, ainsi que chez des mouches provenant de la même population naturelle, mais élevées en laboratoire dans des conditions de consanguinité pendant 15 et 16 générations. La variation de la longueur des spermatozoïdes chez les mâles est significative et c'est un caractère qui se retrouve lors des accouplements subséquents, tant chez les mouches consanguines que non consanguines. La longueur des spermatozoïdes peut donc servir de marqueur mâle individuel lors des études de compétition

\footnotetext{
Received 20 July 2006. Accepted 3 November 2006.

${ }^{1}$ Corresponding author (e-mail: giorgina.bernasconi@unil.ch).

${ }^{2}$ Present address: University of Lausanne, Department of Ecology and Evolution, CH-1015 Lausanne, Switzerland.
} 
spermatique et le fait que la longueur des spermatozoïdes se retrouve dans les générations suivantes est un indice qui appuie l'hypothèse qu'il s'agit d'une caractéristique héritable.

[Traduit par la Rédaction]

\section{Introduction}

Inbreeding has been found to affect fitness and fitness-related traits in plants and animals (Keller and Waller 2002). Inbreeding may negatively affect traits associated with reproduction and reproductive success, such as gametic quality, if increased homozygosity adversely affects spermatogenesis. Low genetic diversity has been found to correlate with sperm morphology in a number of free-living vertebrates, with structurally abnormal sperm being significantly more prevalent in inbred populations (e.g., lions, Wildt et al. 1987a; cheetahs, Wildt et al. $1987 b$ ). This increased frequency of sperm abnormalities leads to reduced reproductive performance in comparison with more genetically diverse populations (Packer et al. 1991). While we are not aware of any study of the effects of inbreeding on sperm features in invertebrates, environmental stressors such as diet and disease have been implicated in abnormal spermatozoal morphology and size variation in several insects (Sait et al. 1998; Blanckenhorn and Hellriegel 2002; Hellriegel and Blanckenhorn 2002).

Sperm length is a highly variable trait across species (e.g., Cummins and Woodall 1985; Pitnick and Markow 1994; Gage et al. 1998), although an adaptive explanation for the variation remains elusive (Gage et al. 1998). Across some taxa, higher levels of polyandry and thus sperm competition risk are associated with longer sperm (e.g., butterflies, Gage 1994; nematodes, LaMunyon and Ward 1998; birds, Briskie et al. 1997), but this does not appear to be the case in all taxa (see e.g., Parker 1993).

There is also considerable intraspecific variation in sperm size at several levels. For example, some taxa produce several sperm morphs (e.g., snails, Oppliger et al. 1998; flies, Snook and Karr 1998; Joly et al. 2004; butterflies, Silberglied et al. 1984; Cook and Gage 1995; insects, Bernasconi and Hellriegel 2005). The adaptive functions of the different morphs are not entirely understood, but in moths, for example, they may play a role in delaying female receptivity (Cook and Gage 1995). Variation in sperm length is also found within sperm morphs or in sperm-monomorphic species
(Levitan 1993; Radwan and Siva-Jothy 1996; Oppliger et al. 1998; Sait et al. 1998; Simmons et al. 1999; Ward 2000a; Morrow and Gage 2001). For some taxa, it has been shown that among-male variation is repeatable across ejaculates (Morrow and Gage 2001; Simmons et al. 2003).

Unfortunately variation at this level has been the subject of few studies, and its evolutionary consequences are largely conjectural (Ward 1998; Simmons and Kotiaho 2002). However, intraspecific, interindividual variation is unlikely to be selectively neutral. Indeed, larger amoeboid sperm are more successful at sperm competition in mites (Radwan and Siva-Jothy 1996) and nematodes (LaMunyon and Ward 1998).

The yellow dung fly (Scathophaga stercoraria (L.); Diptera, Scathophagidae) is sperm monomorphic but shows significant interindividual variation in sperm length (Ward and Hauschteck-Jungen 1993). Interindividual variation in sperm length appears to be consistent across several ejaculates (Hellriegel and Bernasconi 2000), but the repeatability of this character has not been directly addressed. There is some evidence that variation in sperm length influences sperm storage (Otronen et al. 1997).

The aims of this study were to assess amongmale variation and within-male stability of sperm length in yellow dung flies and to investigate the effect of inbreeding on sperm length. The results have bearing on the variability of a gametic trait and its plasticity. Moreover, they support the applicability of sperm length as a marker of individual males, e.g., for sperm competition studies.

\section{Materials and methods}

The dung fly Scathophaga stercoraria belongs to a mainly Holarctic family with over 250 species (Bernasconi et al. 2001) and has been an important model for studies of sexual selection for over 30 years (Parker 1970; Ward 2000b; Simmons 2001; Martin et al. 2004). Here, we investigate the effect of inbreeding on among-male variation and within-male repeatability of sperm length in dung flies kept in the 
laboratory for 1,15 , and 16 generations. Flies were collected at Feraltorf, near Zurich, Switzerland, in 1996 and 1998. Flies from the first collection were kept for 16 generations in the laboratory and selected for the three phosphoglucomutase (Pgm) alleles most common in Swiss populations (Ward 2000b). The lines were derived from a limited number of individuals and were thus inbred. During selection, brother-sister matings were avoided, ensuring that as much genetic variability as possible was maintained. By the time they were used in the experiments described here, these inbred flies were homozygous for one Pgm allele. Flies from the second collection were kept for one generation under the same laboratory conditions $\left(20{ }^{\circ} \mathrm{C}, 13 \mathrm{~L}: 11 \mathrm{D}\right.$; Simmons and Ward 1991). All adult flies were housed individually (females) or in pairs (males) and supplied ad libitum with water, sugar, and prey (Drosophila melanogaster) for 2 to 6 weeks after emergence to ensure full sexual maturation (Foster 1967). To elicit mating behaviour, flies were placed in glass bottles containing oviposition subtrate (a smear of cow dung on a filter paper; see Simmons and Ward (1991) for full descriptions of housing and mating procedures). After experimental matings, female flies were killed under anaesthetic $\left(\mathrm{CO}_{2}\right)$.

To determine variation in sperm length of individual males, each male was mated to four virgin females. In total, we investigated sperm length for replicate males ( $n$ between 14 and 19 per generation, Table 1), each of them mated to four independent replicate females. On day 1, males were allowed one copulation, which was interrupted after $20 \mathrm{~min}$, and on day 2 they were allowed three to four full copulations in sequence. This mating regime is directly comparable to that used in an experiment addressing differential storage of sperm from competing males (Hellriegel and Bernasconi 2000).

We measured copulation duration as observable genitalic contact. Singly mated females were dissected after copulation and their three spermathecae were removed, transferred to a microscope slide with a drop of insect saline, and opened under a microscope. The released sperm was spread out. Dried microslides were briefly washed with distilled water to remove salt crystals. We measured the length of 30 sperm per mating using a dark-field microscope (400x magnification) and a camera that conveyed images to a computer running Optimas ${ }^{\mathrm{TM}}$ image
Fig. 1. Repeatability of sperm length measurement $(\mu \mathrm{m})$ in the yellow dung fly, Scathophaga stercoraria. For each of eight males, 30 sperm on microslides were blindly re-measured. Measurement was highly repeatable, indicating that repeatabilities as calculated over variance components (Results) reflect biologically relevant trait stability.

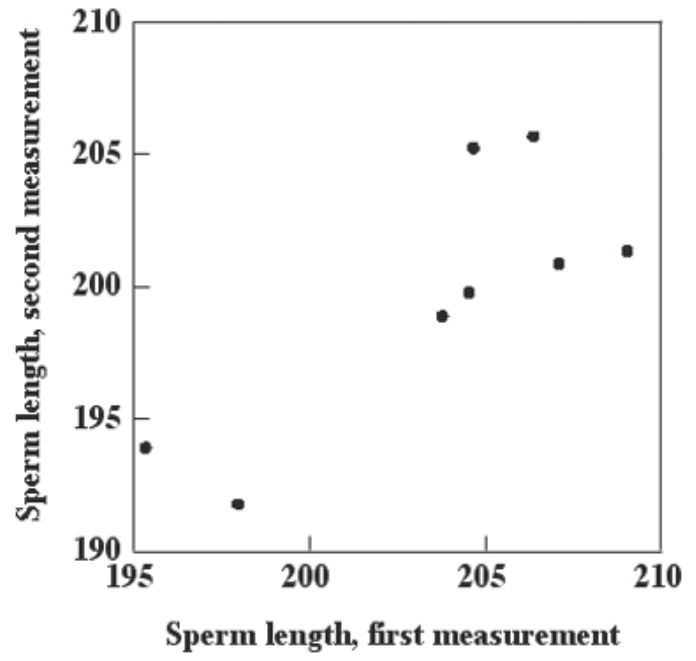

analysis software (BioScan, Edmonds, Washington). We verified that measurement itself was repeatable by re-measuring eight randomly chosen slides (30 sperm per slide) blindly (Fig. 1). Regression between first and second measurements indicated that measurement was repeatable $\left(\beta \pm \mathrm{SE}=0.76 \pm 0.23, F_{1,6}=10.9\right.$, $P=0.016)$. The mean sperm length of each male over four subsequent copulations was then analysed with a repeated-measures ANOVA to estimate among- and within-male variation over time. We calculated the repeatability $(R)$ of sperm length over subsequent matings as $R=$ $V_{\text {among males }} /\left(V_{\text {among males }}+V_{\text {within males }}\right)$, where $V$ is variance. The variance components were calculated as follows: $V_{\text {within males }}=\mathrm{MS}_{\text {within }}$ and $V_{\text {among males }}=\left(\mathrm{MS}_{\text {among }}-\mathrm{MS}_{\text {within }}\right) / k$, where $\mathrm{MS}$ is mean squares and $k$ is the number of replicates corrected for unbalancing (Lessells and Boag 1987). The analysis was carried out using restricted maximum likelihood (Patterson and Thompson 1971), which is equivalent to ANOVA but allows for unbalanced data sets (REML in Genstat 5.4.1, Lawes Agricultural Trust, Rothamsted Experimental Station, Harpenden, United Kingdom). The data and residuals met the requirements of normality and homoscedasticity. 
Table 1. Short-term variation in sperm length and copulation duration of individual Scathophaga stercoraria males over four matings.

\begin{tabular}{lcccc}
\hline Generation & Mating & $\begin{array}{c}\text { Sperm length } \\
(\mu \mathrm{m})\end{array}$ & $\begin{array}{c}\text { Copula duration } \\
(\mathrm{min})\end{array}$ & $\begin{array}{c}\text { Body mass } \\
(\mathrm{mg})\end{array}$ \\
\hline $\mathrm{F}_{1}(n=18)$ & 1st & $206.3 \pm 4.6$ & - & $40.6 \pm 6.0$ \\
& 2nd & $204.5 \pm 4.8$ & $29.7 \pm 9.3$ & \\
& 3rd & $205.2 \pm 5.1$ & $26.3 \pm 8.6$ & \\
$\mathrm{~F}_{15}(n=14)$ & 4th & $205.7 \pm 6.0$ & $23.7 \pm 8.6$ & $42.7 \pm 8.9$ \\
& 1st & $201.7 \pm 5.0$ & - & \\
& 2nd & $201.6 \pm 5.5$ & $36.0 \pm 9.2$ & \\
$\mathrm{~F}_{16}(n=19)$ & 3rd & $202.6 \pm 4.2$ & $26.8 \pm 7.3$ & \\
& 4th & $201.5 \pm 4.3$ & $37.0 \pm 20.0$ & \\
& 1st & $196.7 \pm 5.9$ & - & \\
& 2nd & $198.6 \pm 5.8$ & $36.3 \pm 12.2$ & \\
& 3rd & $198.3 \pm 5.5$ & $31.4 \pm 7.1$ & \\
& 4th & $198.6 \pm 5.8$ & $30.4 \pm 12.1$ & \\
\hline
\end{tabular}

Note: For each mating and each male, 30 sperm cells were measured. The first mating was on day 1 and all subsequent matings were on day 2 of the experiment.

Unless otherwise specified, data are reported as $\bar{x} \pm \mathrm{SD}$. Analyses were carried out using SYSTAT $^{\circledR}$ 7.0.1 (Systat Software Inc., Richmond, California) and Genstat 5.4.1.

\section{Results}

Sperm tended to be longer in $F_{1}$ males than in $\mathrm{F}_{15}$ and $\mathrm{F}_{16}$ males (Table 1). The length of individual sperm cells was highly repeatable across subsequent matings in all generations, as indicated by significant differences among males (Tables 2 and 3). When the analysis was done on mean sperm length per mating as opposed to individual sperm lengths, there were significant differences among males, and the repeatability of mean sperm length was over $70 \%$ in all generations (ANOVA: $\mathrm{F}_{1}, F_{17,54}=14.7$, $\left.P<0.001 ; \mathrm{F}_{15}, F_{12,33}=14.8, P<0.001\right)$.

The effect of time (i.e., repeated copulations) on sperm length was not significant in any of the generations. In contrast, the interaction of time with variation among males was significant, indicating that the amount of change in sperm length over time (and repeated copulations) differed among males. However, these changes were only slight, and the variance component attributable to differences among males over time was substantially lower than amongmale variation in sperm length (Table 3 ).

Male body mass, mean sperm length, and mean copulation duration were not significantly correlated, neither in the whole data set (Spearman's rank correlation, all $P>0.123, n=$ $41)$ nor within generations. Thus, sperm length seems to vary independently of male body mass and mating or mate-guarding behaviour.

\section{Discussion}

We found that individual male dung flies have a characteristic sperm length, with differences among males being significant and consistent over four successive matings. This was the case also for flies subject to several generations of inbreeding: individual males differed consistently in both the $\mathrm{F}_{1}$ and the inbred $\left(\mathrm{F}_{15}\right.$ and $\mathrm{F}_{16}$ ) generations. We found significant repeatability of sperm length within ejaculates (variance component of male effect) but we also found plasticity in sperm length across ejaculates over time (variance component of male $\times$ temporal sequence effect). Plasticity within males was substantially smaller than differences among males. Thus, although inbreeding is known to affect fitness-related traits in many species (Keller and Waller 2002), it did not erode among-male differences in sperm length.

Inbred flies tended to have shorter sperm. Inbred lines were maintained by crossing females with one male each (monandry). Thus, the inbreeding regime in fact relaxes conditions favouring male adaptations to counter sperm competition risk. If longer sperm are more successful at sperm competition, but also costly to produce, relaxing the selection pressure may lead to a decrease in sperm length. However, the fitness effect of variation in male sperm length remains to be investigated. Also, shorter 
sperm in inbred flies may be due to inbreeding and, in addition, may be influenced by environmental conditions in the laboratory (Hellriegel and Blanckenhorn 2002), although every effort was made to standardize conditions.

These results confirm that sperm length can be used as a reliable marker for individual males, for instance to investigate processes of differential sperm storage in multiple spermathecae in studies of male-male competition (Otronen et al. 1997; Hellriegel and Bernasconi 2000). In a study involving doubly mated females allowed 1 day between the first and the second mating, $80 \%$ of the sperm from the spermathecae could be assigned to the competing males by sperm length (Hellriegel and Bernasconi 2000). Given that other spermmonomorphic species have both substantial among-male variability and within-male stability (Morrow and Gage 2001), this method may be applicable to other species as well. A potential caveat is that sperm length may not be neutral with respect to storage. In studies investigating differential storage, this has been accounted for in the experimental design. For instance, randomizing male mating order with respect to relative sperm length and mating the same male pair repeatedly to replicate females are designs that avoid any potential bias due to differences in sperm length (Lewis and Austad 1990; Birkhead 1998; Hellriegel and Bernasconi 2000). Thanks to the increasingly widespread availability of molecular markers, an interesting research avenue would be to follow up paternity success in situations involving sperm competition using both knowledge of sperm size distribution and molecular methods (e.g., quantitative PCR). Such a combined approach should make it possible to determine whether sperm size affects paternity success and thus male fitness. In addition, such an approach would enable the exploration of the relative success of males with very small sperm size differences, while using sperm size alone necessarily requires large between-male differences for identification of individuals.

In conclusion, male dung flies differ consistently in individual sperm length, even when subject to inbreeding for several generations. Thus, although inbreeding has been found to affect fitness-related traits in many taxa, sperm length variation in this species seems to be unaffected. This supports experimental designs using sperm length as an individual male marker

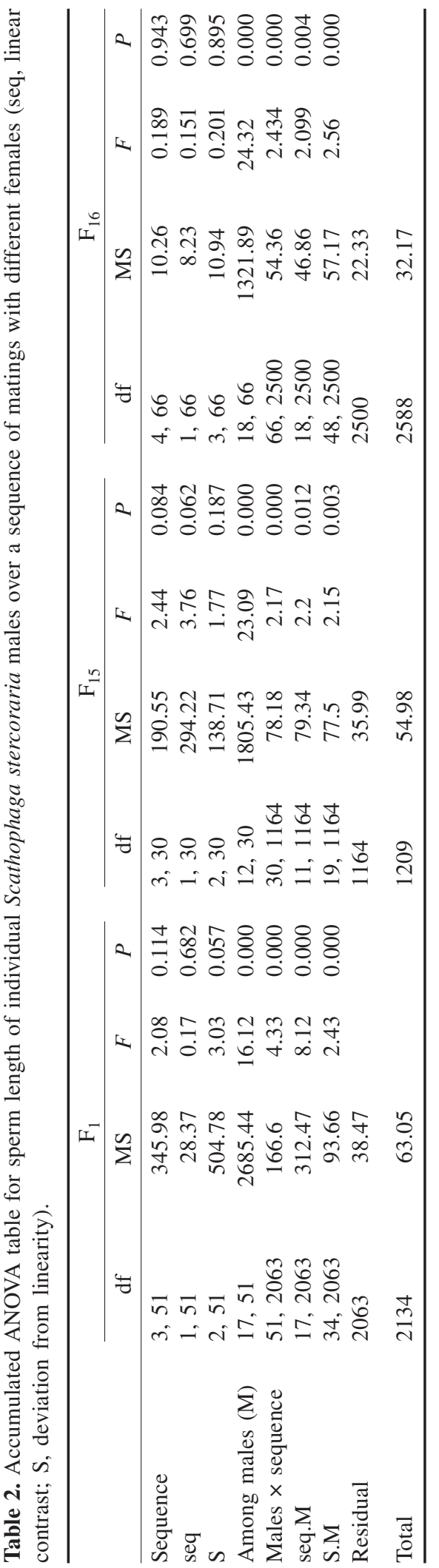

(C) 2007 Entomological Society of Canada 
Table 3. Estimated variance components $\left(\mu \mathrm{m}^{2}, \bar{x} \pm \mathrm{SE}\right)$ and repeatability of sperm length in Scathophaga stercoraria males.

\begin{tabular}{lrrr}
\hline & \multicolumn{1}{c}{$\mathrm{F}_{1}$} & \multicolumn{1}{c}{$\mathrm{F}_{15}$} & \multicolumn{1}{c}{$\mathrm{F}_{16}$} \\
\hline Variance component & & & \\
$\quad$ Male & $21.04 \pm 7.65$ & $17.71 \pm 7.86$ & $9.42 \pm 3.28$ \\
Male $\times$ temporal sequence (M.S) & $4.35 \pm 1.13$ & $1.47 \pm 0.75$ & $1.10 \pm 0.33$ \\
$\quad$ Residual & $38.47 \pm 1.20$ & $36.11 \pm 1.50$ & $22.35 \pm 0.63$ \\
Repeatability & & & \\
$\quad$ Male & 0.33 & 0.32 & 0.29 \\
Male $\times$ temporal sequence (M.S) & 0.07 & 0.03 & 0.03 \\
\hline
\end{tabular}

in sperm competition studies and supports heritable variation in sperm length in this species.

\section{Acknowledgements}

We thank the reviewers for comments, Wolf Blanckenhorn for providing flies, Dieter Burkhard and Andreas Heyland for assistance with experiments, and Bernhard Schmid for statistical advice. We acknowledge financial support from the Swiss National Science Foundation (3100A0-10331/1, PPOOA-102944/1 to G.B.) and the Swiss Federal Program for Academic Recruitment (No. 409 to G.B., No. 167 to B.H.).

\section{References}

Bernasconi, G., and Hellriegel, B. 2005. Fertilization competence and sperm size variation in spermheteromorphic insects. Evolutionary Ecology, 19: 45-54.

Bernasconi, M.V., Pawlowski, J., Valsangiacomo, C., Piffaretti, J.C., and Ward, P.I. 2001. Phylogeny of the genus Scathophaga (Diptera: Scathophagidae) inferred from mitochondrial DNA sequences. Canadian Journal of Zoology, 79: 517-524.

Birkhead, T.R. 1998. Cryptic female choice: criteria for establishing female sperm choice. Evolution, 52: 1212-1218.

Blanckenhorn, W.U., and Hellriegel, B. 2002. Against Bergmann's rule: fly sperm size increases with temperature. Ecology Letters, 5: 7-10.

Briskie, J.V., Montgomery, R., and Birkhead, T.R. 1997. The evolution of sperm size in birds. Evolution, 51: 937-945.

Cook, P.A., and Gage, M.J.G. 1995. Effects of risks of sperm competition on the numbers of eupyrene and apyrene sperm ejaculated by the moth Plodia interpunctella (Lepidoptera: Pyralidae). Behavioral Ecology and Sociobiology, 36: 261-268.

Cummins, J., and Woodall, P. 1985. On mammalian sperm dimensions. Journal of Reproduction and Fertility, 75: 153-175.
Foster, W. 1967. Hormonal-mediated nutritional control of sexual behavior in male dung flies. Science (Washington, D.C.), 158: 1597.

Gage, M.J.G. 1994. Associations between body size, mating pattern, testis size and sperm lengths across butterflies. Proceedings of the Royal Society of London, Series B: Biological Sciences, 258: $247-254$.

Gage, M.J.G., Stockley, P., and Parker, G. 1998. Sperm morphometry in the Atlantic salmon. Journal of Fish Biology, 53: 835-840.

Hellriegel, B., and Bernasconi, G. 2000. Femalemediated differential sperm storage in a fly with complex spermathecae, Scathophaga stercoraria. Animal Behaviour, 59: 311-317.

Hellriegel, B., and Blanckenhorn, W.U. 2002. Environmental influences on the gametic investments of yellow dung fly males. Evolutionary Ecology, 16: 505-522.

Joly, D., Korol, A., and Nevo, E. 2004. Sperm size evolution in Drosophila: inter- and intraspecific analysis. Genetica, 120: 233-240.

Keller, L., and Waller, D. 2002. Inbreeding effects in wild populations. Trends in Ecology and Evolution, 17: 230-241.

LaMunyon, C.W., and Ward, S. 1998. Larger sperm outcompete smaller sperm in the nematode Caenorhaditis elegans. Proceedings of the Royal Society of London, Series B: Biological Sciences, 265: 1997-2002.

Lessells, C.M., and Boag, P.T. 1987. Unrepeatable repeatabilities - a common mistake. The Auk, 104: 116-121.

Levitan, D.R. 1993. The importance of sperm limitation to the evolution of egg size in marine invertebrates. American Naturalist, 141: 517-536.

Lewis, S.M., and Austad, S.N. 1990. Sources of intraspecific variation in sperm precedence in red flour beetles. American Naturalist, 135: 351-359.

Martin, O.Y., Hosken, D.J., and Ward, P.I. 2004. Post-copulatory sexual selection and female fitness in Scathophaga stercoraria. Proceedings of the Royal Society of London, Series B: Biological Sciences, 271: 353-359.

Morrow, E.H., and Gage, M.J.G. 2001. Consistent significant variation between individual males in 
spermatozoal morphometry. Journal of Zoology (London), 254: 147-153.

Oppliger, A., Hosken, D.J., and Ribi, G. 1998. Snail sperm production characteristics vary with sperm competition risk. Proceedings of the Royal Society of London, Series B: Biological Sciences, 265: $1527-1534$.

Otronen, M., Reguera, R., and Ward, P. 1997. Sperm storage in the yellow dung fly Scathophaga stercoraria: identifying the sperm of competing males in separate female spermathecae. Ethology, 103: 844-854.

Packer, C., Pusey, A.E., Gilbert, D.A., Martenson, J., and O'Brien, S.J. 1991. Case study of a population bottle-neck: lions of Ngoronogoro Crater. Conservation Biology, 5: 219-230.

Parker, G.A. 1970. The reproductive behaviour and the nature of sexual selection in Scatophaga stercoraria. II. The fertilization rate and the spatial and temporal relationship of each sex around the site of mating and oviposition. Journal of Animal Ecology, 39: 205-228.

Parker, G.A. 1993. Sperm competition games: sperm size and sperm number under adult control. Proceedings of the Royal Society of London, Series B: Biological Sciences, 253: 245-254.

Patterson, H.D., and Thompson, R. 1971. Recovery of inter-block information when block sizes are unequal. Biometrika, 58: 545-554.

Pitnick, S., and Markow, T.A. 1994. Male gametic strategies: sperm size, testes size, and the allocation of ejaculate among successive mates by the sperm-limited fly Drosophila pachea and its relatives. American Naturalist, 143: 785-819.

Radwan, J., and Siva-Jothy, M.T. 1996. The function of post-insemination mate association in the bulb mite, Rhizoglyphus robini. Animal Behaviour, 52: 651-657.

Sait, S.M., Gage, M.J.G., and Cook, P. 1998. Effects of a fertility-reducing baculovirus on sperm numbers and sizes in the Indian meal moth, Plodia interpunctella. Functional Ecology, 12: 56-62.

Silberglied, R.E., Shepherd, J.D., and Dickinson, J.L. 1984. Eunuchs: the role of apyrene sperm in Lepidoptera? American Naturalist, 123: 255-265.
Simmons, L.W. 2001. Sperm competition and its evolutionary consequences in the insects. Princeton University Press, Princeton, New Jersey.

Simmons, L.W., and Kotiaho, J.S. 2002. Evolution of ejaculates: patterns of phenotypic and genotypic variation and condition dependence in sperm competition traits. Evolution, 56: 1622-1631.

Simmons, L.W., and Ward, P.I. 1991. The heritability of sexually dimorphic traits in the yellow dung fly Scathophaga stercoraria (L). Journal of evolutionary Biology, 4: 593-601.

Simmons, L.W., Tomkins, J.L., and Hunt, J. 1999. Sperm competition games played by dimorphic male beetles. Proceedings of the Royal Society of London, Series B: Biological Sciences, 266: 145150.

Simmons, L.W., Wernham, J., García-González, F., and Dan Kamien, D. 2003. Variation in paternity in the field cricket Teleogryllus oceanicus: no detectable influence of sperm numbers or sperm length, Behavioral Ecology, 14: 539-545.

Snook, R.R., and Karr, T. 1998. Only long sperm are fertilization competent in six sperm-heteromorphic Drosophila species. Current Biology, 8: 291-294.

Ward, P.I. 1998. Intraspecific variation in sperm size characters. Heredity, 80: 655-659.

Ward, P. 2000a. Sperm length is heritable and sexlinked in the yellow dung fly Scathophaga stercoraria (L.). Journal of Zoology (London), 251: 349-353.

Ward, P. 2000b. Cryptic female choice in the yellow dung fly Scathophaga stercoraria (L.). Evolution, 54: 1680-1686.

Ward, P.I., and Hauschteck-Jungen, E. 1993. Variation in sperm length in the yellow dung fly Scathophaga stercoraria. Journal of Insect Physiology, 39: 545-547.

Wildt, D.E., Bush, M., Goodrowe, K.L., Packer, C., Pusey, A.E., Brown, J.L., Joslin, P., and Obrien, S.J. 1987a. Reproductive and genetic consequences of founding isolated lion populations. Nature (London), 329: 328-331.

Wildt, D.E., Obrien, S.J., Howard, J.G., Caro, T.M., Roelke, M.E., Brown, J.L., and Bush, M. $1987 b$. Similarity in ejaculate-endocrine characteristics in captive versus free-ranging cheetahs of two subspecies. Biology of Reproduction, 36: 351-360. 